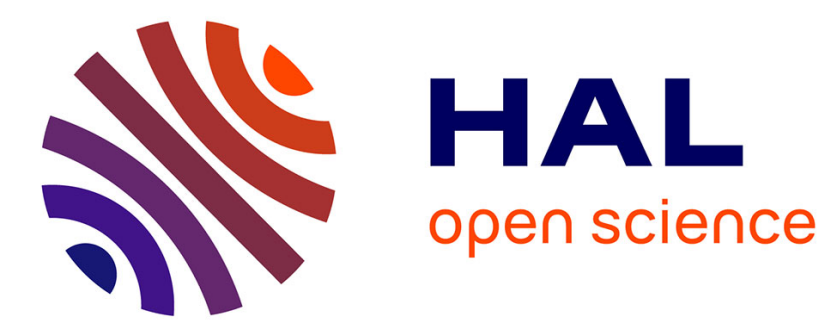

\title{
Study of the Gyromagnetic Resonance Damping in Relaxing Rare Earth Substituted YGd2Fe5O12 Garnets
}

\author{
T. Taffary, H. Pascard, D. Autissier, F. Boust
}

\section{To cite this version:}

T. Taffary, H. Pascard, D. Autissier, F. Boust. Study of the Gyromagnetic Resonance Damping in Relaxing Rare Earth Substituted YGd2Fe5O12 Garnets. Journal de Physique IV Proceedings, 1997, 07 (C1), pp.C1-419-C1-420. 10.1051/jp4:19971169 . jpa-00254815

\section{HAL Id: jpa-00254815 https://hal.science/jpa-00254815}

Submitted on 1 Jan 1997

HAL is a multi-disciplinary open access archive for the deposit and dissemination of scientific research documents, whether they are published or not. The documents may come from teaching and research institutions in France or abroad, or from public or private research centers.
L'archive ouverte pluridisciplinaire HAL, est destinée au dépôt et à la diffusion de documents scientifiques de niveau recherche, publiés ou non, émanant des établissements d'enseignement et de recherche français ou étrangers, des laboratoires publics ou privés. 


\title{
Study of the Gyromagnetic Resonance Damping in Relaxing Rare Earth Substituted $\mathrm{YGd}_{2} \mathrm{Fe}_{5} \mathrm{O}_{12}$ Garnets
}

\author{
T. Taffary, H. Pascard*, D. Autissier and F. Boust** \\ CEA-DAM, BP. 12, 91680 Bruyères-le-Châtel, France \\ * École Polytechnique, Laboratoire SESI, 91128 Palaiseau cedex, France \\ ** ONERA OM, BP. 72, 92322 Châtillon cedex, France
}

\begin{abstract}
The influence of magnetic state (saturated or unsaturated states) on the gyromagnetic resonance damping in relaxing rare earth substituted $\mathrm{X}_{1-\mathrm{x}} \mathrm{Dy}_{\mathrm{x}} \mathrm{Gd}_{2} \mathrm{Fe}_{5} \mathrm{O}_{12}$ garnets (with $\mathrm{x}=0 ; 0.15 ; 0.3 ; 0.6$ ) has been studied. The damping parameter $\alpha$, as defined by Landau-Lifshitz equation, has been determined either by FMR at 10GHz (saturated state) or by measurement of the frequency dependence of the complex initial permeability in the $0.1 \mathrm{GHz}-10 \mathrm{GHz}$ band (unsaturated state). On the one hand, the damping parameter $\alpha_{\text {sat }}$ has been calculated by fitting the FMR spectra of single crystals with the theoretical lorentzian shape. On the other hand, the damping parameter $\alpha_{\text {umsat }}$ of polycrystals has been calculated using models which take into account the interaction between magnetic domains. In the fully magnetized state the introduction of relaxing rare earth (Dy) is found to increase significantly $\alpha_{\text {sat }}$ values (from 0.02 to 0.3 when $x$ varies from 0 to 0.6 ). On the contrary, the introduction of Dy hardly increases $\alpha_{\text {unsat }}$ values. It appears that the difference between $\alpha_{\text {sat }}$ and $\alpha_{\text {unsat }}$ values stems not only from the interaction between magnetic domains but also from the modification of the damping in each magnetic domain owing to the presence of magnetic domain walls.
\end{abstract}

\section{INTRODUCTION}

The comparison between the saturated state and the unsaturated one seems to be a sensible way to better understand the relaxation of ferrimagnetic materials in the unsaturated state. The proper parameter to describe relaxation is the damping parameter which can be introduced in Landau-Lifshitz equation $\frac{d \vec{M}}{d t}=-|\gamma| \overrightarrow{\mathrm{M}} \wedge \vec{B}_{\text {eff }}-\frac{\alpha|\gamma|}{\|\vec{M}\|} \vec{M} \wedge\left(\vec{M} \wedge \vec{B}_{\text {aff }}\right)$ where $\gamma$ is the gyromagnetic factor, $\mathbf{B}_{\text {eff }}$ the effective magnetic field acting on the magnetization vector $\mathbf{M}$ and $\alpha$ the damping parameter. To make the comparison effective, materials presenting different damping behaviours are required. That is why we have chosen $\mathrm{Y}_{1-\mathrm{x}} \mathrm{Dy}_{\mathrm{x}} \mathrm{Gd}_{2} \mathrm{Fe}_{5} \mathrm{O}_{12}$ garnets. Indeed, studies on YIG [1] have shown that Dy substitution in dodecahedral sites is achievable and provides a good way of varying the damping in the saturated state. Furthermore, for the welcoming structure $\mathrm{YGd}_{2} \mathrm{Fe}_{5} \mathrm{O}_{22}$, the domain resonance and the gyromagnetic one are separated enough [2] to allow the study of the latter.

After describing the experimental procedure used for preparing the materials and for characterizing their microwave properties, we shall present and discuss the experimental results obtained in the saturated state and then in the unsaturated state. Finally, the conclusion takes up the comparison between both states.

\section{EXPERIMENTAL PROCEDURE}

Materials have been prepared by reaction sintering. Oxides powders of high purity $\left(\mathrm{Y}_{2} \mathrm{O}_{3}, \mathrm{Gd}_{2} \mathrm{O}_{3}, \mathrm{Dy}_{2} \mathrm{O}_{3} 99.99 \%\right.$ and $\mathrm{Fe}_{2} \mathrm{O}_{3} 99.7 \%$ ) are blended in water for 12 hours, dried at $120^{\circ} \mathrm{C}$ for 24 hours. Then the materials are shaped by uniaxial pressing at $130 \mathrm{MPa}$ and finally sintered at temperatures ranging from $1400^{\circ} \mathrm{C}$ to $1500^{\circ} \mathrm{C}$. Porosities of all studied samples are less than $2 \%$. A discontinuous grain growth occuring when the sintering temperature exceeds $1460^{\circ} \mathrm{C}$ has led to grain size up to a few millimeters. Single crystal spheres have been cut out of these large grains. The other samples are polycrystalline with an average grain size of tens of micrometers.

Two kinds of microwave measurements have been achieved. On the one hand, FMR measurements have been caried out in the $X$ band frequency range $(10 \mathrm{GHz})$ using a Varian EPR spectrometer on single crystal and polycrystalline spheres about 0.3 millimeters diameter introduced in a $\mathrm{TE}_{102}$ rectangular resonant cavity. On the other hand, the frequency variation of the permeability has been measured using a HP 8510 network analyser on polycrystalline toroidal samples placed in a coaxial wave guide at the APC7 standard. 


\section{SATURATED STATE}

FMR spectra of single crystals and their theoretical fitting using Landau-Lifshitz equation are given in figure 1. Agreement is excellent and allows to determine the total linewidth. Classically [3 ], $\Delta B_{\text {total }}=\Delta B_{R E}+\Delta B_{\text {roughness }}+\Delta B_{\text {porosity }}$ ( $R E=$ Rare Earth). For our materials the calculations of the different contributions shows that $\Delta B_{\text {roughnes }}$ and $\Delta B_{\text {porosity }}$ are very small compared to $\Delta B_{R E}$ so that $\Delta B_{\text {total }}=\Delta B_{R E}$ and $\alpha_{s a t}=\Delta B_{R E} /\left(2 B_{r}\right)$ can be determined. Linewidth and frequency variations with rare earth concentration are in agreement with Kittel theory [4] on rare earth gamets.

No significant change has been observed for measurements made on polycrystalline samples. We then have at our disposal a familly of materials with damping parameter ranging from 0.02 to 0.3 (one order of magnitude).

\section{UNSATURATED STATE}

The effects of Dy substitution in the unsaturated state are shown in figure 2 . The domain wall resonance (at roughly $0.2 \mathrm{GHz}$ ) and the gyromagnetic resonance $(0.6 \mathrm{GHz})$ are distinctly separated. When Dy is introduced, the domain wall resonance completely disappears and the gyromagnetic one is strongly damped.

The experimental curves can no longer be fitted by LandauLifshitz equation because of the interaction between magnetic domains. This was first taken into account qualitatively by [5] and quantitatively by [6 ]. More recently, [7 ] have developed the model of the effective permeability which we have used to fit our experimental curves. Agreement has turned out to be of poor quality but has nevertheless led to orders of magnitude (precision +0.1 ) : the introduction of Dy slightly increases $\alpha$ unsat values from 0.2 to 0.5 .

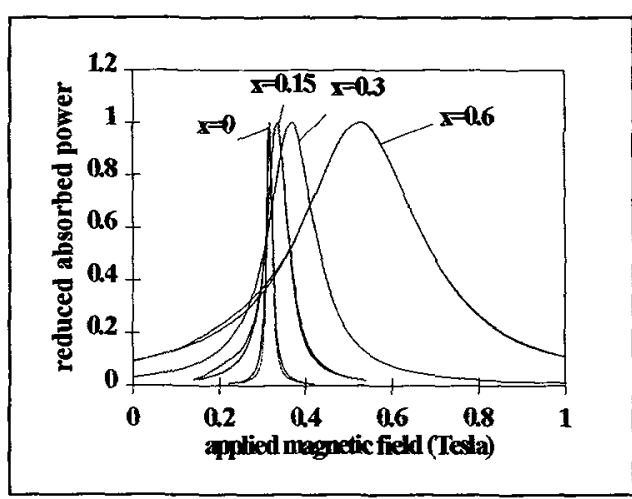

Figure 1 : FMR spectra $(9.4 \mathrm{GHz})$ in the saturated state on $\mathrm{Y}_{1-x} \mathrm{Dy}_{\mathrm{x}} \mathrm{Gd}_{2} \mathrm{Fe}_{5} \mathrm{O}_{12}$ single crystal spheres.

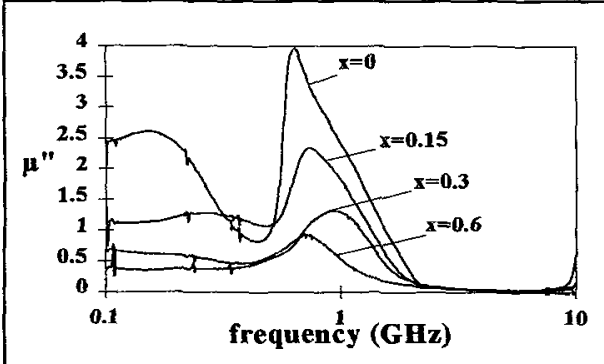

Figure 2 : imaginary part of the permeability in the unsaturated state on $\mathrm{Y}_{1-\mathrm{x}} \mathrm{Dy}_{\mathrm{x}} \mathrm{Gd}_{2} \mathrm{Fe}_{5} \mathrm{O}_{12}$ polycrystalline toroïds.

\section{CONCLUSION : COMPARISON BETWEEN SATURATED AND UNSATURATED STATE}

From figure 3, we can see that $\alpha_{\text {unsat }}$ is greater than $\alpha_{\text {sat. }}$. Moreover, the ratio $\alpha_{\text {unsat }} / \alpha_{\text {sat }}$ is all the more important as Dy concentration is low. This may be explained by the fact that the model used does not take into account the presence of domain walls. Therefore, one can suggest that domain walls should modify the damping in each magnetic domain. Two mechanisms would then be in competition : the "intrinsic" damping of an isolated domain and the interaction of domain walls and a magnetic domain. At low concentration, the dominant relaxation mechanism would be the interaction between a magnetic domain and its neighbouring domain walls. At high concentration, dynamics interaction would be weakened so that intrinsic relaxation inside each domain would drive the overall relaxation : $\alpha$ sat and $\alpha_{\text {unsat }}$ would be of the same order of magnitude.

Further investigations involving the application of a static magnetic field while measuring $\mu^{\prime}$ and $\mu$ "' are to be published .

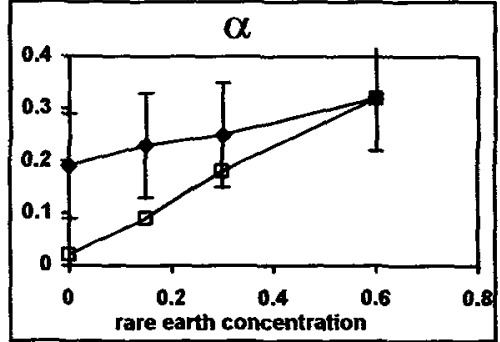

Figure 3 ; damping parameters $\alpha$. -unsaturated state $\square=$ saturated state

\section{References}

1 Harrison. G. R, Hodges. L. R, Phys. of Electronic ceramics, part B, chapt. 26, 857-911, M. Dekker, Ind, NewYork (1972).

2 Cagan. V, Pascard. H and Globus. A, Jour. of Magnetism and Magnetic Materials, 15-18, 1980, 555-556.

3 Sparks. M, Ferromagnetic Relaxation, Mc Graw, 1964.

4 Kittel. C, Journal of Physical Review, volune 115 (6), September 15, 1969, 1587-1590.

5 Polder. D and Smit. J, Rev. Mod. Phys., 1953, 25, 89.

6 Schlomann. E, (a) J. of Appl. Phys, vol. 41(1), 1970, 204-214. (b) J. de Phys., Colloque C1, suppl. n'2-3, 1971, C1-443.

7 Bouchaud. J. P and Zerah. P. G, Joumal. of Applied Physics, vol. 67 (9), May 1990, 5512-5514. 